Article available at nttp://www.parasite-Journal.org or nttp://dx.dol.org/10.1051/parasite/200108s2120

\title{
POSSIBLE PRESENCE OF COMMON TYVELOSE-CONTAINING GLYCANS IN TRICHINELLA LI LARVAE AND EMBRYONATED EGGS OF SEVERAL NEMATODES
}

\author{
DEA-AYUELA M.A.*, ROMARÍS F.**, UBEIRA F.M.**, RAMA-IÑIGUEZ S.*, \\ MARTÍNEZ-FERNÁNDEZ A.R.* \& BOLÁS F.*
}

\section{Summary :}

A monoclonal antibody (mAb US4) recognising an epitope containing tyvelose within the $T$. spiralis $L-1$ muscle larvae (TSL-1) antigens was tested in western-blot against various antigenic preparations from different stages of the following nematodes: T. spiralis (LI, adult), T. muris legg, LI, L3, adult), Ascaris suum (egg, adult), Toxocara canis (egg, adult), Anisakis simplex (L3) and Haemochus contortus (egg). Positive reaction was present in antigen preparations from LI larvae of T. spiralis and T. muris and from embryonated eggs of $T$. muris, A. suum, $T$. canis and H. contortus.

KEY WORDS : TSL-1 antigens, tyvelose, glycans, Trichinella, nematodes.

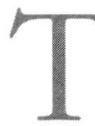
ISL1 antigens are a group of glycoproteins that express an immunodominant carbohydrate epitope (Ortega-Pierres et al., 1996). They primarily locate at the cuticle surface and in the alpha- and beta-stichocyte granules of the muscle larvae of Trichinella spiralis (Ellis et al., 1994) but are absent in adult worms. Fine structural analysis of this carbohydrate led to identification of a 3,6-dideoxy-D-arabinohexose (Tyvelose) (Wisnewski et al., 1993), an unusual sugar previously found in gram-negative bacteria and in the ascaroside alcohols of the Ascaris eggs (Jezyk \& Fairbairn, 1967) although in a different isomeric form. More recently it has been shown that tyvelose is the terminal residue of a tetrasaccharide epitope(Ellis et al., 1997).

In previous studies a monoclonal antibody (mAb) named US4 was characterised as recognising an epitope containing tyvelose within the TSL1 antigens (Romaris et al., unpublished results). In the present work we investigate the presence of this tyvelosecontaining glycans in other helminths.

\footnotetext{
* Departamento de Parasitología, Facultad de Farmacia, Universidad Complutense, 28040-Madrid, Spain.

** Departamento de Microbiología y Parasitología, Facultad de Farmacia, Universidad de Santiago, 15706, Santiago de Compostela, Spain.

Correspondence: F. Bolás.

Tel.: 34-91394 1818 - Fax: 34-91-394 1815.

E-mail: bolas@eucmax.sim.ucm.es
}

\section{MATERIAL AND METHODS}

\section{PARASITES}

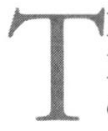
the following parasites and stages were used: L1 larvae and adult worms from $T$. spiralis (isolate GM-1 MFEL/SP/63/ISS48), embryonated (EE) and non-embryonated eggs (NEE); L1, L3 and adult worms from Trichuris muris (Edimburgh isolate); eggs at different embryonic stages (EE 1-3 months) and adult worms from Ascaris suum; EE and adult worms from Toxocara canis; EE from Haemonchus contortus and L3 larvae from Anisakis simplex.

\section{ANTIGENS}

Crude saline extracts (CSE) from larvae and adult worms were prepared by sonication. Crude extracts from eggs (ECSE) were prepared by freeze-thaw in liquid N2 followed by manual homogenisation and sonication.

Excretory/secretory (ES) products from L1 larvae of T. spiralis and adult worms from T. muris were obtained by incubating worms in MEM + Earle's salts added with L-glutamine, Hepes and antibiotics, for 24 hours.

\section{MONOCLONAL ANTIBODY}

The monoclonal antibody (mAb) US4 was obtained by Dr. Ubeira (Dept. Microbiology and Parasitology, University of Santiago de Compostela, Spain) in immunodefficient mice expressing the Xid-gene, following infection with L1 larvae and further immunization with the cytosolic fraction of T. spiralis L1 larvae (ISS 48 isolate). It is of the IgG1K isotype (Romaris et al., unpublished results).

\section{ELECTROPHORESIS AND WESTERN-BLOTTING}

SDS PAGE was carried out following conventional methods using the Mini-Protean system (Bio-Rad). Samples (aprox. 5-10 $\mu \mathrm{g}$ ) were run in 5-20\% gradient gels under reducing conditions. Separated protein bands were visualised by silver staining. 
Western-blotting was carried out according to standard protocols. The mAb US4 was used at 1:10000. Immunoreactive bands were detected using horseradish peroxidase-labeled anti-mouse IgG + IgM (Caltag) at 1:3000 dilution and 4-chloro-1-naphthol as substrate.

\section{RESULTS}

T The recognition profiles in western-blot of $\mathrm{mAb}$ US4 with different antigen preparations is summarised in Figure 1. Among larval stages positive reaction was only present in CSE and ES from L1 larvae of T. spiralis and T. muris with a triplet of bands between 49 and $53 \mathrm{kDa}$ plus an additional one at $66 \mathrm{kDa}$ in T. spiralis and one band of about $60 \mathrm{kDa}$ in T. muris. Positive reactions were also observed in CSE from embryonated eggs of all species with two bands at about 55 and $60 \mathrm{kDa}$ in T. muris, two bands at about 60 and 65 in T. canis and H. contortus and one band of $55 \mathrm{kDa}$ in $A$. suum. No recognition was apparent in CSE from non-embryonated eggs of all species.

\section{DISCUSSION}

The results from this preliminary study seem to show that the epitope recognised by mAb US4 is restricted to the early stages of nematode life cycles as only L1 infective larvae or embryonated eggs containing infective stages show positive reaction. Further immunocytochemical studies are required for a precise localisation of this epitope, either in the infective larvae or in the layers of the egg shell containing these infective larvae. In any case, this restriction to infective stages could indicate a role in penetration and establishment of these nematodes within the intestine of their hosts. Regarding chemical nature of the epitope targeted by mAb US4 it was suggested to be a tetrasaccharide containing tyvelose as this mAb was specifically inhibited by the synthetic tetrasaccharide $\beta$-D-Tyv-(1,3)- $\beta$-D-GalNAc- $(1,4)-[\alpha-L-F u c-(1,3)]-\beta-D-$ GlcNAc- (Romaris et al., unpublished results).

Non-specific binding of mAbs US4 to carbohydrates is unlikely as recognition is restricted to embryonated eggs and L1 stages despite that highly carbohydrate content is shown by the other stages. Furthermore, no

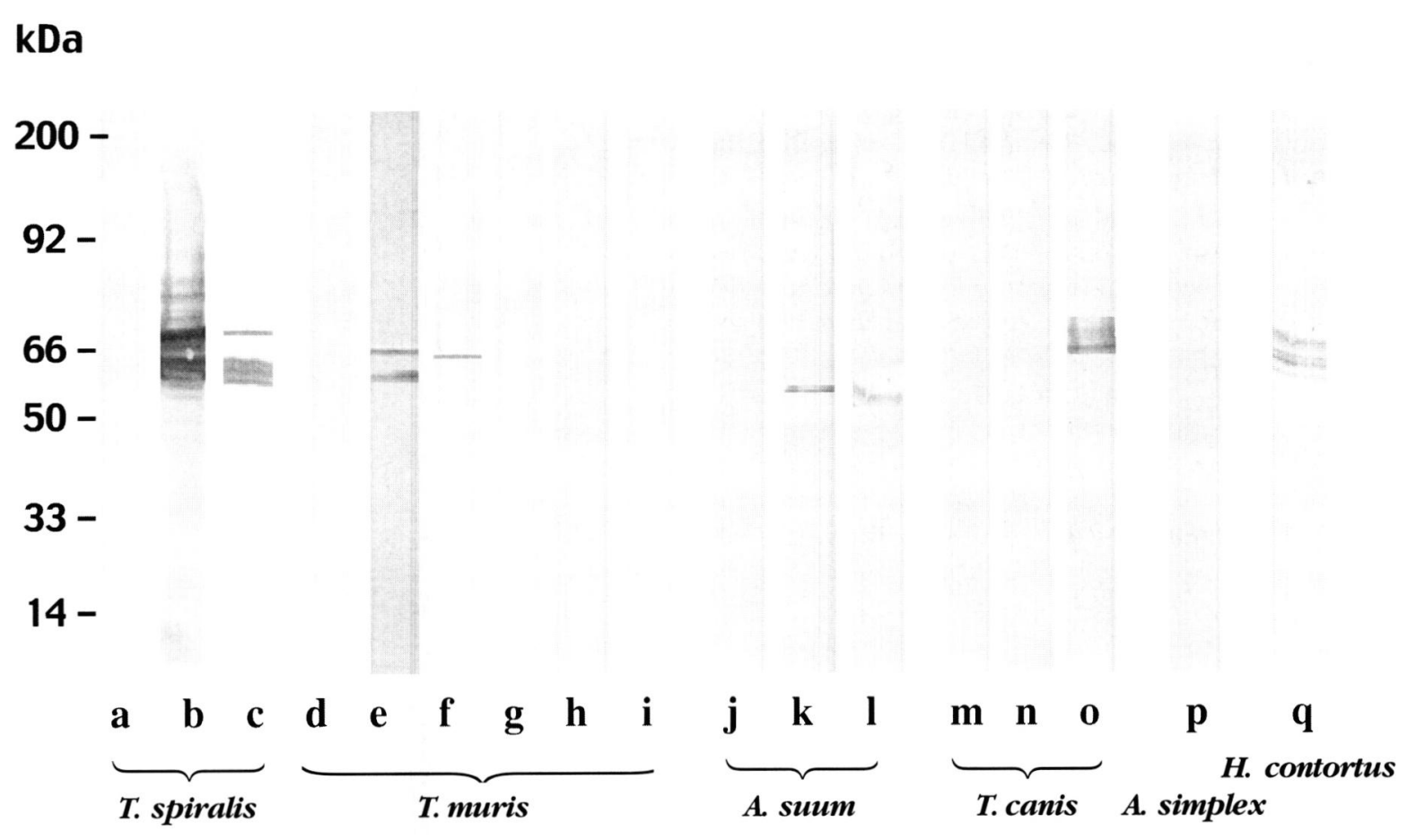

Fig. 1. - Recognition profiles of mAb US4 in western-blot with various antigen preparations from several stages of Trichinella spiralis and other nematodes. a. CSE from adults, b. CSE from L-1 larvae, c. ES from L-1 larvae, d. CSE from non-embryonated eggs, e. CSE from embryonated eggs, $\mathbf{f}$. CSE from L-1 larvae, $\mathbf{g}$. CSE from L-3 larvae, $\mathbf{h}$. CSE from adults, i. ES from adults, $\mathbf{j}$. CSE from adults, $\mathbf{k}$. CSE from one month embryonating eggs, 1. CSE from three month embryonating eggs, $\mathbf{m}$. CSE from adults, $\mathbf{n}$. CSE from non-embryonated eggs, o. CSE from embryonated eggs, p. CSE from L-3 larvae, q. CSE from embryonated eggs.

$\mathrm{CSE}=$ crude saline extract, $\mathrm{ES}=$ excretory-secretory products . 
positive reaction was observed with other mAbs (named US5, US9) of the same subclass (data not shown).

\section{ACKNOWLEDGEMENTS}

The authors wish to thank the following colleagues for kindly providing the parasite samples: Dr. I. Navarrete (eggs from A. suum), Dr. M. Fenoy (eggs from T. canis), Dr. G. Miró-Corrales (eggs from H. contortus) and Dr. Cuellar (adult worms from $T$. canis and A. suum and L3 larvae from Anisakis simplex). This work was partially funded by project FIS $n^{\circ} 00 / 0787$.

\section{REFERENCES}

Appleton J.A., Schain L.R. \& McGREGor D.D. Rapid expulsion of Trichinella spiralis in suckling rats: mediation by monoclonal antibodies. Immunology, 1988, 65, 487-492.

Ellis L.A., Reason A.J., Morris H.R., Dell A., Iglesias R., Ubeira F.M. \& APPLETON J.A. Glycans as target for monoclonal antibodies that protect rats against Trichinella spiralis. Glycobiology, 1994, 4, 585-592.

Ellis L.A., McVay C.S., Probert M.A., Zhang J., Bundle D.R. \& Appleton J.A. Terminal $\beta$-linked tyvelose creates unique epitopes in Trichinella spiralis glycan antigens. Glycobiology, 1997, 7, 383-390.

JEZYK P.F. \& FAIRBAiRn D. Ascarosides and ascaroside esters in Ascaris lumbricoides (Nematoda). Comparative Biochemical Physiology, 1967, 23, 691-705.

Ortega-Pierres G., Yepez-Mulia L., Homan W., Gamble H.R., Lim P.I., TAKahashi Y., Wassom, D.L. \& Appleton J.A. Workshop on a detailed characterization of Trichinella spiralis antigens: a platform for future studies on antigens and antibodies to this parasite. Parasite Immunology, 1996, 18, 273-284.

Wisnewski N., MCNeIl M., Grieve R.B., \& Wassom D. Characterization of novel fucosyl-and tyvelosyl-containing glycoconjugates from Trichinella spiralis muscle stage larvae. Molecular and Biochemical Parasitology, 1993, 61, 25-36. 